\title{
El hombre y la técnica en Ortega y Gasset
}

\section{Man and technology in Ortega y Gasset's thought}

Fernando H. Llano Alonso. Profesor Titular de Filosofía del Derecho

Universidad de Sevilla. $\underline{\text { llano@us.es }}$

RESUMEN: El presente estudio indaga en torno a las claves humanistas de la relación entre el hombre y la técnica en el pensamiento de José Ortega y Gasset. La aproximación a este tema por parte del filósofo del raciovitalismo tiene especial relevancia por la originalidad de su tesis, absolutamente contemporánea y diferente tanto de los planteamientos cuasi apocalípticos defendidos por otros pensadores de su tiempo, por ejemplo, Spengler, como de la lectura poshumanista de la técnica realizada por Heidegger. La meditación sobre la técnica que lleva a cabo nuestro autor va desde los años treinta a los cincuenta y ve en la combinación del progreso técnico con las humanidades una gran oportunidad para la creación o la invención de un mundo nuevo en el que los hombres no tendrán que enfrentarse al dilema de dominar o someterse a la naturaleza, sino que deberán afrontar otro desafío distinto: el que representa esa "sobrenaturaleza” que constituyen las nuevas tecnologías.

ABSTRACT. This study explores around the humanist keys of the relationship between man and technology in José Ortega y Gasset's thought. The approach to this subject that the philosopher of rational-vitalism holds has a special relevance for the originality of his thesis, absolutely modern and different both from the almost apocalyptical stances that other thinkers of his time held, Spengler for instance, and from the post-humanist reading held by Heidegger. The pondering about technology that our author carries out goes from the nineteen thirties to the nineteen fifties and sees in the combination of technological progress with the humanities a great opportunity for the creation or invention of a new world where men will not have to face the dilemma of either dominating or submitting to nature, but instead they will have to face a challenge of a different kind: the one represented by that "overnature" or "supernature" that the new technologies form.

Palabras clave: Humanidades, tecnología, ciencia, raciovitalismo

Key Words: Humanities, technology, science, rational-vitalism 


\section{INTRODUCCIÓN}

La pregunta sobre la relación entre el hombre y la técnica constituye uno de los tópicos filosóficos más antiguos y recurrentes de la historia del pensamiento occidental desde la Antigua Grecia hasta el presente. En el inicio mismo de la actividad filosófica puede apreciarse cómo el espíritu heleno se preocupó por buscar una respuesta a esta cuestión a través de dos posiciones antitéticas o contrapuestas: de un lado, la búsqueda de una explicación verosímil, racional y objetiva a través del razonamiento (logos); de otro lado, el recurso a la imaginación y a la fuerza de persuasión que proporciona el cuento o el relato (mythos). En todo caso, el método de pensamiento mítico era familiar tanto a los filósofos profesionales (Platón), como a los poetas (Hesíodo) (Grimal, 1982: 97). En efecto, mientras Platón crea en El Banquete una fábula alegórica sobre la génesis de la humanidad, Hesíodo, por su parte, inventa una de las versiones más populares del mito del titán Prometeo que sirve para un doble propósito: en primer lugar, para ilustrar simbólicamente el origen del hombre (no en vano, a Prometeo, como padre de Decaulión, se le considera el antepasado de los hombres); en segundo lugar, para cifrar en el descubrimiento del fuego el comienzo de la técnica, es decir, el dominio consciente de la Naturaleza por y para la humanidad (Von Klinckowstroem, 1980: 515-516) ${ }^{1}$.

El debate contemporáneo en torno a la crisis de la sociedad de las Nuevas Tecnologías no puede entenderse en su plenitud sin una obligada referencia a ese remoto hombre auroral que se encuentra por azar con la técnica y que, con el paso del tiempo, aprende primero a coexistir con ella, más tarde aspira a dominarla para transformar su mundo y, finalmente, termina convirtiéndose en lo que Ortega y Gasset denomina metafóricamente un centauro ontológico, esto es, un ser “que media porción de él está inmersa, desde luego, en la naturaleza, pero la otra parte trasciende de ella” $(\mathrm{V}, 570)^{2}$. Es sabido que, en relación con la coexistencia entre el hombre y la técnica, se ha pretendido dilucidar muchas veces quién predomina sobre quién en dicha relación y en qué términos se produce ésta. Es verdad que el hombre crea y se sirve de la técnica como instrumento; pero también es cierto que la técnica

\footnotetext{
${ }^{1}$ Según la versión del mito de Prometeo que nos relata Hesíodo, este titán (a diferencia de sus hermanos Atlas, Meneceo y Epimeteo) no pretendía combatir el poder de Zeus desplegando solamente la fuerza física, sino por medio de las armas del espíritu, la astucia y el engaño.

${ }^{2}$ En el presente trabajo citaré los trabajos de Ortega y Gasset según la nueva edición de sus Obras completas que ha preparado la Fundación José Ortega y Gasset-Gregorio Marañón en coedición con Taurus. En adelante se citará en romanos el volumen correspondiente al trabajo objeto de referencia, y en arábigos las páginas en las que se encuentre el texto subrayado.
} 
Llano Alonso, Fernando H.: “El hombre y la técnica en Ortega y Gasset”, IUS ET SCIENTIA, 2015, Vol. 1, No. 1, pp. 1-24

DOI: http://dx.doi.org/10.12795/IETSCIENTIA.2015.i01.02

determina la vida humana hasta tal punto que, sin aquella, ésta no sería hoy concebible. Por eso, la pregunta por la técnica adquiere especial significado en un tiempo como el nuestro, en el que se ha podido constatar el fenómeno social al que, a principios de la década de los '70, Daniel Bell se refirió como “el advenimiento de la sociedad postindustrial” (Bell, 1973).

A propósito de la transformación experimentada por la sociedad moderna a partir del desarrollo tecnológico, algunos pensadores (Jacques Ellul, Lewis Mumford, Langdom Winner y Merritt Roe Smith) han planteado a lo largo del siglo XX sus reservas a la supuesta racionalidad del cambio tecnológico (Mumford, 1934; Ellul, 1962; Winner, 1977 y 1986; Smith-Marx, 1994). Para estos autores, cuya posición escéptica acerca del futuro de la sociedad tecnológica se conoce como “determinismo tecnológico”, la tecnología se habría convertido en un sistema autónomo, "en una especie de nuevo y peligroso Leviathan que arrasa con su dinámica todos los sistemas humanos, económicos, políticos, culturales y cualquier tipo de relación entre individuos y grupos” (Broncano, 2000: 29). De acuerdo con esta versión ético-política y normativa del determinismo tecnológico, el impulso emancipador propiciado prima facie por el progreso científico y tecnológico a las sociedades industriales, podría verse comprometido si, en última instancia, el desarrollo de los grandes sistemas tecnológicos lograra escapar del control de la sociedad para acabar imponiendo a ésta su propia racionalidad, es decir, unos dictados cuya lógica interna constituirían una amenaza para la autonomía individual.

Al hilo de la visión crítica de la sociedad tecnológicamente avanzada, en donde la desconfianza hacia el progreso científico-técnico parece haberse convertido en un dogma, los integrantes de la Escuela de Frankfurt, y de manera muy especial Herbert Marcuse, han adoptado una actitud apocalíptica frente a los efectos perversos a los que puede arrastrarnos el progreso tecnológico (Pérez Luño, 2004: 103-107 y 2012: 85)³. Como alternativa a esta deriva tecnicista, propone Marcuse cambios sociales, políticos y culturales que contribuyan a liberar a la tecnología -que per se no es intrínsecamente nociva para el individuo ni para la vida social- de toda forma de autoritarismo que pretenda el uso (o abuso) de la tecnología como forma de dominio. En este sentido advertirá este autor:

\footnotetext{
${ }^{3}$ Esta actitud apocalíptica frente al progreso tecnológico tendría su contrapunto argumental en la posición que mantienen los integrados, es decir, aquellos que ven normal e incluso se consideran satisfechos por la omnipresencia de la técnica en todos los ámbitos de nuestra vida pública y privada. A propósito de ambas actitudes básicas frente a la sociedad tecnológica y la cultura de masas, que fueron definidas por vez primera en un libro de Umberto Eco que responde al mismo nombre: Apocalittici e integrati (1965), resultan de gran interés las consideraciones realizadas por A. E. PÉREZ LUÑO (2004: 103-107 y 2012: 85).
} 
Llano Alonso, Fernando H.: “El hombre y la técnica en Ortega y Gasset”, IUS ET SCIENTIA, 2015, Vol. 1, No. 1 , pp. 1-24

DOI: http://dx.doi.org/10.12795/IETSCIENTIA.2015.i01.02

“El pensamiento científico moderno, en tanto que es puro, no proyecta metas prácticas particulares ni formas particulares de dominación (...) Hoy, la dominación se perpetúa y se difunde no sólo por medio de la tecnología sino como tecnología, y la última provee la gran legitimación del poder político en expansión, que absorbe todas las esferas de la cultura.

En este universo, la tecnología también provee la gran racionalización para la falta de libertad del hombre y demuestra la imposibilidad técnica de ser autónomo, de determinar la propia vida. Porque esta falta de libertad no aparece ni como irracional ni como política, sino más bien como una sumisión al aparato técnico que aumenta las comodidades de la vida y aumenta la productividad del trabajo" (Marcuse, 1964: 158).

Paradójicamente, la fuerza liberadora de la tecnología -a partir de la instrumentalización de las cosas- termina degenerando y convirtiéndose en un encadenamiento de la liberación, o lo que es igual, en la instrumentalización del hombre. Por consiguiente, señala Marcuse, a fin de evitar que la racionalidad tecnológica acabe legitimando la dominación y, lo que sería aún peor, dando aliento a la configuración de sociedades racionalmente totalitarias, es necesario establecer una suerte de intermediación entre la naturaleza, el hombre y la técnica. Esta sería una estructura alternativa de acción alternativa a técnica existente, un proyecto que tendría a la naturaleza como interlocutor e integraría a toda la especie humana. Siguiendo este razonamiento marcusiano, Habermas ha insistido en la necesidad de hallar un punto de encuentro entre el progreso científico-técnico y lo que él denomina "el mundo social de la vida”. En otras palabras, Marcuse y Habermas parecen apostar por una visión más humana de la técnica cuya propuesta sería una alternativa válida tanto al determinismo tecnológico, como al neocientificismo, en la medida en que ambos modelos entrañan instrumentos de dominio y opresión dificultarían precisamente "la práctica de la vida en las grandes sociedades industriales” (Habermas, 1965: 118).

Se ha podido afirmar oportunamente que los pensadores afiliados a la Escuela de Frankfurt percibieron que, junto a la de la temporalidad del ser, la cuestión tecnológica -en particular, la relación entre el hombre y la técnica- era el elemento más definitorio en el debate sobre la modernidad, hasta el punto de haber determinado su discurso a lo largo del siglo XX (Navajas, 2007). Ahora bien, no sólo para los representantes de esta Escuela (en la que también cabría incluir a Theodor W. Adorno, e indirectamente a Walter Benjamin), sino en general para otros filósofos de su generación -la del 14- como Oswald Spengler, Martin Heidegger y José Ortega y Gasset, tiene sentido preguntarse por la vigencia social de la técnica contemporánea, pero también por el lugar que ésta ocupa en el conjunto de la cultura 
Llano Alonso, Fernando H.: “El hombre y la técnica en Ortega y Gasset”, IUS ET SCIENTIA, 2015, Vol. 1, No. 1, pp. 1-24

DOI: http://dx.doi.org/10.12795/IETSCIENTIA.2015.i01.02

(Atencia, 2003: 62). En realidad este fue el transfondo teórico del que partió el Coloquio de Darmstadt de 1951, en el que se enfrentaron dos interpretaciones diferentes sobre el humanismo y la técnica: por un lado, la visión ontológica de Heidegger, convencido de que la técnica moderna se nos ha ido tanto de las manos que, por ello, "sólo un dios puede aún salvarnos” (Heidegger, 1989: 71) para el que la técnica y el hombre están esencialmente tan imbricados que se podría llegar a sostener que: “el hombre empieza cuando empieza la técnica” (V, 574).

A raíz de la polémica conferencia dictada por Peter Sloterdijk, en el verano de 1999, con el título: "Reglas para el parque humano. Una carta de respuesta a la Carta sobre el humanismo", en la que, siguiendo la estela del Zaratustra nietzscheano y del posthumanismo heideggeriano, el profesor de la Universidad de Karlsruhe decretó el fin del humanismo moderno y domesticador del hombre, y su sustitución por una política antropotécnica (Sloterdijk, 2003: 77), parece haberse reanudado el debate sobre el futuro de la sociedad tecnológica y el lugar que le corresponde ocupar al humanismo en ella. En este contexto general cabe plantearse si hemos entrado en una era posthumanista o si, por el contrario, nos hallamos ante un resurgimiento del proyecto ilustrado de la modernidad, un proyecto este que -según Habermas- se encuentra aún incompleto (Habermas, 1998: 27 y 32). En cualquier caso, parece una duda razonable el preguntarse cuántos de esos discursos filosóficos elaborados a lo largo del siglo XX sobre la técnica resultan todavía hoy válidos para entender el universo de las Nuevas Tecnologías (Molinuevo, 2000: 5-6). En un tiempo como el nuestro, donde las fronteras entre lo real y lo artificial aparecen a veces tan difuminadas, tal vez no tenga ya mucho sentido pretender la reforma, a través de la técnica, de una naturaleza que el hombre extraña, y acaso se pueda justificar más fácilmente el hecho de aspirar a crear una nueva realidad producida artificialmente (técnicamente) por y para el hombre. Por eso mismo, plantear -como hizo Ortega hace más de setenta años- la posibilidad de un humanismo tecnológico, entendido como una visión alternativa al enfoque apocalíptico de la técnica defendido por algunos filósofos francfortianos, y a la postura posthumanista heideggeriana, nos lleva también a comprobar la actualidad de uno de sus textos más emblemáticos y genuinos de Ortega: la Meditación sobre la técnica (1939).

\footnotetext{
${ }^{4}$ Véase la entrevista que hizo a Heidegger la revista Der Spiegel, el 23 de septiembre de 1963 (publicada póstumamente, en el número 23 de la revista, el 31 de mayo de 1976). También Spengler se refirió anteriormente a una idea salvífica y desesperanzada respecto a la pérdida de una técnica faústica, propia de la cultura occidental europea y norteamericana, en beneficio de una técnica maquinista que se utiliza solo como instrumento de dominio (Spengler, 1967: 64-69).
} 
Llano Alonso, Fernando H.: “El hombre y la técnica en Ortega y Gasset”, IUS ET SCIENTIA, 2015, Vol. 1, No. 1, pp. 1-24

DOI: http://dx.doi.org/10.12795/IETSCIENTIA.2015.i01.02

El presente trabajo partirá, por tanto, del enfoque antropológico de la técnica que nos propone Ortega y Gasset en este libro (aunque, como se verá, no es la única en la que reflexiona sobre la técnica y su dimensión humana); posteriormente, una vez hecha la oportuna caracterización de la técnica en Ortega, se estudiarán las afinidades y las diferencias que presenta su tesis en comparación con la idea de la técnica que tienen algunos de sus contemporáneos, pero muy especialmente con respecto al punto de vista defendido por su principal rival en términos teóricos: Martin Heidegger; por último, se analizarán las claves de la actualidad y el interés que aún ofrece la Meditación sobre la técnica en nuestro tiempo, el de las Nuevas Tecnologías de la información y la telecomunicación (Echeverría, 2000: 1921).

\section{LA INSERCIÓN DE LA TÉCNICA EN EL PROYECTO RACIOVITALISTA DE ORTEGA Y GASSET}

Existe una cierta relación de causalidad entre la filosofía raciovitalista de Ortega y su interpretación antropológica de la técnica, según la cual, la técnica pertenece a la esencia de lo humano. A este respecto, convendría recordar que, cuando nuestro autor publica en 1939 la Meditación de la técnica, en realidad está recapitulando un ciclo de conferencias dictadas en el estío de 1933 en la Universidad de Santander (en el seno de lo que hoy se conocen como los cursos de verano de la Universidad Internacional Menéndez Pelayo), y que llevaban precisamente por título: ¿Qué es la técnica? Dos años más tarde, el diario bonaerense La Nación publicaría en doce artículos estas lecciones. Como puede apreciarse, el libro que aparece publicado en $1939^{5}$, y precedido del texto titulado Ensimismamiento y alteración, pertenece en realidad al género del ensayo y la meditación. Sin embargo, aunque esta obra de Ortega se considera como un trabajo de plena madurez, todavía será objeto de una reelaboración posterior, tras la conferencia que nuestro autor dictará en Darmstadt en $1951^{6}$. Sin embargo, según el testimonio del propio Ortega, sus meditaciones en torno a la técnica se remontan a los años 1927 y 1928, es decir, justamente durante el período en el que ultima su proyecto raciovitalista -en el cual se entiende la vida como realidad radical-, que expone en

\footnotetext{
${ }^{5}$ Según ha revelado José Luis Molinuevo, Meditación de la técnica fue publicado "ante la labor pirata de los editores de Chile, que recortaban esos artículos (publicados en La Nación) dándolos en forma de libro”. (Molinuevo, 2000: 6).

${ }^{6}$ Al hilo de esta conferencia aparecerán publicados un año después dos trabajos trascendentales para entender la idea de técnica en Ortega: "En torno al coloquio de Darmstadt. 1951" y "El mito del hombre allende la técnica" (1952), VI, 797-810 y 811-817, respectivamente.
} 
Llano Alonso, Fernando H.: “El hombre y la técnica en Ortega y Gasset”, IUS ET SCIENTIA, 2015, Vol. 1, No. 1 , pp. 1-24

DOI: http://dx.doi.org/10.12795/IETSCIENTIA.2015.i01.02

Buenos Aires en 1928, y del que saldrán sus libros: ¿Qué es filosofía? (1928) y La rebelión de las masas (1930).

"Mi libro La rebelión de las masas va inspirado, entre otras cosas, por la espantosa sospecha que sinceramente sentía entonces -allá por 1927 y 1928, nótenlo ustedes, las fechas de la prosperity- de que la magnífica, la fabulosa técnica actual corría peligro y muy bien podría ocurrir que se nos escurriese de entre los dedos y desapareciese en mucho menos tiempo de cuanto se puede imaginar. Hoy, cinco años después, mi sospecha no ha hecho sino acrecentarse pavorosamente. Vean, pues, los ingenieros cómo para ser ingeniero no basta con ser ingeniero. Mientras se están ocupando en su faena particular, la historia les quita el suelo de debajo de los pies.

Es preciso estar alerta y salir del propio oficio: otear bien el paisaje de la vida, que es siempre total. La facultad suprema para vivir no la da ningún oficio ni ninguna ciencia: es la sinopsis de todos los oficios y todas las ciencias y muchas otras cosas además. Es la integral cautela. La vida humana y todo en ella es un constante y absoluto riesgo. La media toda se va por el punto menos previsible: una cultura se vacía entera por el más imperceptible agujero..., recapacite el técnico no más que comparando su situación de ayer con la que hace presumir el mañana.” (V, 564).

Aunque Ortega haga una crítica ponderada de la sociedad de masas, no dejará por ello de incorporar a su proyecto raciovitalista lo que hay de positivo en este fenómeno. La rebelión de las masas puede convertirse en una catástrofe para el destino de los hombres, pero también supone una oportunidad para avanzar hacia una nueva organización de la humanidad (IV, 421). Para nuestro autor, el hombre-masa actual es "un primitivo, que por los bastidores se ha deslizado en el viejo escenario de la civilización” (IV, 424); no obstante, este mismo primitivismo del hombre-masa, que desprecia radicalmente los principios de la civilización, no le impide sentirse atraído por la técnica. Esta es la misma conclusión a la que llegan otros pensadores contemporáneos de Ortega, como Spengler y Heidegger. Sin embargo, a diferencia de sus dos colegas germanos (Spengler, 1993: 584; Molinuevo, 1999: 80), para los que el hombre de su tiempo queda atrapado en la técnica, enajenado y absorbido por la misma maquinaria que él mismo creó -como sucede en la alegórica escena de una de las mejores películas de Charles Chaplin: Tiempos modernos $(1936)^{7}$ - Ortega entiende que la técnica es esencial al hombre, de modo que sin técnica no hay hombre. En otras palabras, la 
Llano Alonso, Fernando H.: "El hombre y la técnica en Ortega y Gasset”, IUS ET SCIENTIA, 2015, Vol. 1, No. 1, pp. 1-24

DOI: http://dx.doi.org/10.12795/IETSCIENTIA.2015.i01.02

técnica es un modo de ser del hombre condicionado por el modo en que está en la naturaleza, circunstancia o mundo.

Por otro lado, la técnica es consustancialmente ciencia; pero la ciencia -advierte Ortegano existiría si fuera incapaz de suscitar el interés de la gente por su pureza. En última instancia, la continuidad de esa atracción popular por la ciencia dependerá de que la gente siga entusiasmada con los principios generales de la cultura. Una vez más, Ortega vuelve a mostrar su desacuerdo con Spengler, según el cual, la técnica sobrevive incluso cuando muere el fervor de la gente por los principios culturales; para nuestro autor, por el contrario, la técnica es incapaz de vivir sin el impulso cultural que la creó. A esta idea se refiere precisamente Ortega cuando señala que: "se vive con la técnica, pero no de la técnica” (IV, 424). Conviene tener en cuenta esta advertencia sobre el radical interés del hombre-masa por la técnica y de su desinterés radical hacia la cultura porque, aunque no se puede soslayar la realidad del progreso, es preciso corregir la noción que cree seguro dicho avance, sin la amenaza de involución y retroceso. En definitiva, concluye Ortega, ni el primitivismo técnico del hombre-masa, ni su pasión tecnológica, garantizan nada, y mucho menos la perduración de la técnica (IV, 425).

Cuando, en la primera parte de su ensayo Meditación de la técnica, Ortega se refiere a las condiciones de posibilidad de la técnica en realidad está aludiendo al hecho de que el hombre posee una "inteligencia técnica" que nos explica cómo puede éste inventar nuevos métodos e instrumentos, pero no nos aclara por qué necesita inventarlos. Y es que, según Ortega, el hombre no hace la técnica porque posea una especial aptitud para ello, sino porque su ser, es decir, su vida entendida como realidad radical así lo requiere. Justamente en este vínculo entre técnica y vida humana es donde estriba la singularidad de la meditación orteguiana sobre la ontología de la técnica humana. En este sentido conviene añadir que, si bien es cierto que el hombre, como el resto de los animales, es un ser que existe en un medio natural y que, además de necesidades, tiene un repertorio de aptitudes para satisfacerlas, sin embargo, lo que distingue al hombre de las demás criaturas del reino animal es su capacidad para modificar la correspondencia entre necesidades, aptitudes y condiciones favorables del medio (Riu, 2010: 47 ss.). En otras palabras, cuando el hombre no halla en el medio las facilidades necesarias, por ejemplo, fuego para calentarse, lejos de resignarse -como hacen los animales- recurre a otras aptitudes que tienen como finalidad producir lo que no brinda la

\footnotetext{
${ }^{7}$ En esta película Chaplin interpreta a un obrero de la industria siderúrgica que trabaja apretando tuercas en una cadena de montaje, y que acaba perdiendo la razón (en otras palabras: termina siendo deshumanizado por la máquina que le absorbe literalmente dentro de su complejo mecanismo de engranajes).
} 
circunstancia: en este caso, hacer fuego. En eso consiste, ni más ni menos, la técnica: en la reforma de la naturaleza, de esa naturaleza que nos hace "necesitados y menesterosos", de manera que las necesidades quedan anuladas en la medida en que su satisfacción ha dejado de ser un problema. Por consiguiente, esta reacción contra su entorno, este inconformismo y falta de resignación es lo que caracteriza al hombre, que utiliza la técnica para adaptar el medio a su medida. A esta inadaptación del hombre a la naturaleza apela Ortega cuando afirma que: "Un hombre sin técnica, es decir, sin reacción contra el medio, no es hombre" $(\mathrm{V}, 559)$.

De modo que la técnica es la reforma de la circunstancia natural. En lugar de someterse y de identificarse con las necesidades objetivas que el medio impone a los animales, el hombre se distancia de esa naturaleza en la que está, y lo hace ensimismándose, esto es, liberándose de ella a través de una respuesta técnica que interioriza, lo cual le permite adaptar el medio a su circunstancia, produciendo lo que para él es auténticamente necesario, esto es, lo superfluo, lo que no había antes en la naturaleza. Como podrá apreciarse, a diferencia de la interpretación objetivista que otros autores contemporáneos suyos hacen de la técnica -por ejemplo, Scheler o Spengler- como "el conjunto de los recursos de una ciencia, o de un arte, en orden a satisfacer sus necesidades” (Cordero, 2002: 170), la visión que tiene Ortega de la necesidad es subjetiva, en la medida en que está condicionada por la voluntad de vivir del hombre; y la vida, como realidad radical es, después de todo, un quehacer cotidiano de cada individuo en el que las necesidades son subjetivadas por éste. En resumidas cuentas, para Ortega, hombre, técnica y bienestar son términos sinónimos, por eso dice que el hombre es esencialmente técnico, porque en él existencia y bienestar son una misma cosa.

Abundando en la visión raciovitalista de la técnica humana, hay que convenir que, aunque en primera instancia pueda causar cierta perplejidad el hecho de que nuestro autor sostenga que "el hombre no es naturaleza, sino que tiene...historia” (VI, 73), esta cita cobra pleno sentido si se conecta con el razonamiento anterior: que el hombre no es una cosa estática, sino que su realidad es dinámica, de igual forma que su vida no le viene dada, hecha ni regalada, sino que consiste en un continuo hacerse para no dejar de ser o existir. Por lo tanto, el hombre es una aspiración, una inquietud, un proyecto vital pendiente de realización, una permanente lucha dentro una determinada circunstancia por llegar a ser aquello que su voluntad decida ser (V, 570-571).

Esta concepción humanista de la técnica encuentra en ella el medio para crear necesidades superfluas, lo cual responde perfectamente al empeño del hombre por vivir (una vez que ha colmado la necesidad biológica y primaria de sobrevivir), y por estar en el mundo 
Llano Alonso, Fernando H.: “El hombre y la técnica en Ortega y Gasset”, IUS ET SCIENTIA, 2015, Vol. 1, No. 1, pp. 1-24

DOI: http://dx.doi.org/10.12795/IETSCIENTIA.2015.i01.02

lo mejor posible, placenteramente, con bienestar (liberando tiempo y energía en pro de aquello que es atractivamente inútil) y, por ello, constituye el fin mismo de su vida, de una vida que trasciende la realidad natural y que, como se verá en el siguiente epígrafe, es “inventada” por el hombre. A este respecto, comentará Ortega:

“El hombre, quiera o no, tiene que hacerse a sí mismo, autofabricarse” (V, 573).

\section{LA INVENCIÓN DE LA VIDA A TRAVÉS DE LA TÉCNICA: TRES MODELOS HUMANOS PARA LA PROYECCIÓN DEL SER}

El hombre carece de naturaleza, pero es un ser técnico dispuesto a consumar una tarea extranatural: la creación de una sobrenaturaleza en la que poder proyectar su ser; por eso, la misión inicial de la técnica consiste precisamente en "dar franquía al hombre para poder vacar hacia sí mismo” (V, 574). La técnica es así la expresión de la ontología del hombre, un ser entregado a la tarea de construir e imaginar su propia realidad, la de una circunstancia y un mundo que son solo suyos. La vida humana es, por tanto, vida inventada, de tal forma que el hombre vendría a ser:

“una especie de novelista de sí mismo que forja la figura fantástica de un personaje con su tipo irreal de ocupaciones y que para conseguir realizarlo hace todo lo que hace, es decir, es técnico” (V, 567).

Entre los diversos programas vitales en los que el hombre ha concentrado históricamente su ser, Ortega distingue tres modelos coincidentes en la extranaturalidad de su elección vital, pero diferentes en su modo de enfrentarse técnicamente a la circunstancia natural: en primer lugar, el proyecto del bodhisatva hindú; en segundo lugar, el programa del gentleman inglés; y, finalmente, el ideal de vida del hidalgo español. Estos tres modelos producen técnicas diversas, de manera que el pueblo en que predomina la idea de que el verdadero ser del hombre es el bodhisatva, no puede crear una técnica igual a aquellos otros en que se aspira a ser gentleman o hidalgo (V, 578 ss.).

En relación con el bodhisatva, aclara Ortega, la verdadera existencia consiste en no ser individuo, partícula del universo, sino fundirse extáticamente con el Todo y desaparecer en él. En este sentido, escribirá nuestro autor: "El bodhisatva, pues, aspira a no vivir o a vivir lo menos posible”. Por eso, aunque no resulta probable que, dada su inmovilidad, el bodhisatva 
Llano Alonso, Fernando H.: “El hombre y la técnica en Ortega y Gasset”, IUS ET SCIENTIA, 2015, Vol. 1, No. 1, pp. 1-24

DOI: http://dx.doi.org/10.12795/IETSCIENTIA.2015.i01.02

llegue a inventar el automóvil como el hombre occidental, lo que sí desarrollará más será, en cambio, las técnicas del éxtasis, técnicas que -según Ortega- no producen reformas en la naturaleza material, sino en el cuerpo y en la psique del hombre. La propuesta vital del bodhisatva, que consiste en existir como meditador y como extático, "en constante procuración de anular el mundo y la existencia misma”, no es -para el pensador madrileñoun modo natural de existir. Por ello, el suyo es un ejemplo drástico de la extranaturalidad del ser humano y de lo difícil que es su realización en el medio físico (V, 579).

Al contrario que el bodhisatva hindú, el gentleman de la Inglaterra victoriana desea vivir con intensidad en este mundo y potenciar lo más posible su individualidad. Sin embargo, puntualiza Ortega, este modo de ser hombre no implica el aristocratismo. A diferencia del aristócrata continental -el Junker alemán o el gentilhomme de Versalles- el gentleman, como tal, no es el heredero de fortuna, grandes medios de vida y que, por ende, no ha tenido que luchar en ésta para conquistarlos. El gentleman, al contrario del aristócrata europeo, supone que el hombre tiene que luchar en la vida, que ejercitar todas las profesiones y oficios, sobre todo los prácticos (puesto que el gentleman tampoco es intelectual). De aquí que el gentleman represente un prototipo de existencia que vale para todo el mundo: “el burgués y el obrero -sostiene Ortega- pueden, en cierta medida, ser gentleman” $(\mathrm{V}, 581)^{8}$.

Por último, Ortega introduce un tercer tipo ejemplar de vida que conserva lo mejor del gentleman, pero que "lleva en sí la condición de florecer en tierra de pobreza”: el hidalgo español del siglo XVI. Sin embargo, si bien es cierto que el hidalgo es el tipo humano que más se parece al gentleman, en la medida en que ambos saben darle a sus condiciones de existencia una solución digna, lo que más separa al hidalgo español del gentleman inglés es que el hidalgo no trabaja, y que, afirma Ortega:

“reduce al extremo sus necesidades materiales y, en consecuencia, no crea técnicas, Vive alojado en la miseria como esas plantas del desierto que saben vegetar sin humedad”(V, 584).

\section{TRES GRANDES ESTADIOS EN LA EVOLUCIÓN DE LA TÉCNICA}

Con esta clasificación de programas vitales del hombre, en los que se muestran también diferentes clases de técnica, Ortega se situaba frente a la tendencia doctrinal reinante en su

\footnotetext{
${ }^{8}$ Algunos autores, (Moro, 2001: 220; Mermall, 2010: 127), han interpretado que el gentleman del que nos habla Ortega ofrece un ethos que vendría a ser una variante del tipo de alma noble que figura en La rebelión de las
} 
Llano Alonso, Fernando H.: “El hombre y la técnica en Ortega y Gasset”, IUS ET SCIENTIA, 2015, Vol. 1, No. 1, pp. 1-24

DOI: http://dx.doi.org/10.12795/IETSCIENTIA.2015.i01.02

época, que consideraba únicamente había una técnica (la europeo-americana), y que todo lo demás era solo "un torpe rudimento y balbuceo hacia ella” (V, 587). Por este motivo, teniendo en cuenta que el hombre ha sido siempre un ser técnico, Ortega no entiende la razón por la que se ha soslayado este pasado técnico de la humanidad y se le reconoce exclusivamente esta condición al hombre contemporáneo. Al fin y al cabo, la técnica, como cualquier otra dimensión humana, es histórica y ha atravesado por una serie de etapas. En este sentido, a fin de conocer detalladamente la evolución de las técnicas humanas a lo largo de la historia y de entender los cambios sustantivos que engendraron nuestra técnica actual, nuestro autor propone una periodización de la historia de la técnica en tres grandes estadios: en primer lugar, el estadio más remoto y primitivo, el que corresponde a la técnica del azar; en segundo lugar, en la Antigüedad grecorromana y la Edad Media nos encontramos el estadio la técnica del artesano y, en tercer lugar, en la Edad Moderna y Contemporánea, nos hallamos ante el estadio de la técnica del técnico.

En este primer estadio, “el azar es el técnico, el que proporciona el invento” (V, 590). Es la técnica propia del hombre primitivo y de algunas tribus actuales que ignoran su propia técnica como tal, es decir, no advierten que, entre sus capacidades, hay una que les permite reformar la naturaleza en el sentido de sus deseos. Esta ignorancia está condicionada por diversos hechos: a) porque el repertorio técnico es muy reducido y, por ello, los actos técnicos apenas se pueden destacar de los actos naturales, lo cual equivale a decir que "el primitivo es mínimamente hombre y casi todo él puro animal”; b) porque la sencillez y escasez de esa técnica primigenia facilita el que sus actos puedan ser ejercitados por todos los miembros de la colectividad; c) porque el primitivo tampoco cobra conciencia del momento más característico de la técnica: el de la invención. En definitiva, escribe Ortega:

“Este hombre, pues, no se sabe a sí mismo como inventor de sus inventos. La invención le aparece como una dimensión más de la naturaleza -el poder que ésta tiene de proporcionarle ella a él, y no al revés, ciertos poderes. La producción de utensilios no le parece provenir de él, como no provienen de él sus manos y sus piernas. No se siente homo faber” (V, 590-591).

En cuanto al segundo estadio, el correspondiente a la técnica del artesano, propia de la Antigua Grecia, la Roma pre-imperial y la Edad Media. Sus principales caracteres son: a) los actos técnicos son más numerosos y complejos que los del hombre primitivo. Ya no puede

masas, o sea "el ejemplar en el que se engendra la virtuosidad de lo técnico como juego limpio [...] como enseñoramiento de lo superfluo”. 
Llano Alonso, Fernando H.: “El hombre y la técnica en Ortega y Gasset”, IUS ET SCIENTIA, 2015, Vol. 1, No. 1 , pp. 1-24

DOI: http://dx.doi.org/10.12795/IETSCIENTIA.2015.i01.02

ejercer la técnica cualquiera, sino solamente el artesano; b) en la artesanía no se concibe aún la conciencia del invento. El artesano aprende su oficio técnicas heredadas de una insondable tradición en la que los maestros transmiten sus conocimientos técnicos a los aprendices. En esta época, por consiguiente, no se sabe que existe la técnica, pero sí que hay técnicos para ejercerla; c) la idea de técnica aún no se desprende y aísla de la idea del hombre que la realiza, y es que todavía el inventor sólo ha llegado a producir instrumentos y no máquinas; d) sino surge todavía en este segundo estadio una conciencia adecuada de la técnica es debido a que el artesano simultanea dos funciones: por una parte, la invención de un plan de actividad, método o procedimiento (mechané), y por otra, la ejecución de dicho plan. En todo caso, se trata de dos funciones que la tecnología posterior -la correspondiente al tercer estadio- se encargará de disociar, al separar radicalmente al obrero del técnico (V, 594-595).

La transición al tercer estadio, el de la técnica del técnico, se produce cuando el hombre adquiere conciencia de que la técnica no es un azar, como en el estadio primitivo, ni una específica y limitada actividad ejecutada por un determinado profesional: el artesano, sino precisamente "un hontanar de actividades humanas, en principio, ilimitadas”. Ahora bien, esta conciencia de la ilimitación produce en el hombre un sentimiento de frustración y azoramiento, porque -según Ortega- al aparecer la técnica como capacidad ilimitada, hace que al hombre, puesto a vivir de fe en la técnica y sólo en ella, se le vacíe la vida. Ser solamente técnico conlleva poder serlo todo y consecuentemente nada determinado. Por decirlo con las palabras de nuestro autor:

“De puro llena de posibilidades, la técnica es mera forma hueca -como la lógica más formalista-; es incapaz de determinar el contenido de la vida. Por eso estos años en que vivimos, los más intensamente técnicos que ha habido en la historia humana, son los más vacíos” $(\mathrm{V}, 596)$.

A tenor de estas palabras, y pese a la aparente desconfianza que la técnica moderna suscita en el pensador madrileño, conviene advertir que, como ha observado con agudeza Pietro Piro, para Ortega, la técnica entraña sin duda un peligro, pero también una posibilidad. Frente al pesimismo que embargaba a otros pensadores de su tiempo, como por ejemplo Spengler, para el que la técnica moderna no es más que un signo demostrativo de la decadencia de la humanidad, a juicio de Ortega la técnica es una especie de recipiente vacío que puede ser rellenado de estulticia y desesperación, pero también de bienestar e ilusión, e incluso puede ser útil para mejorar las condiciones de vida humana (Piro, 2012: 71). 


\section{EL DEBATE SOBRE EL HOMBRE Y LA TÉCNICA ENTRE ORTEGA Y HEIDEGGER: EL COLOQUIO DE DARMSTADT}

La cuestión sobre la técnica siguió siendo objeto de meditación por parte de Ortega incluso después de la publicación de su tesis en forma de artículos, y luego de libro, en la década de los '30; de hecho, tras su regreso del exilio y el inicio de la reconstrucción de Europa una vez terminada la Segunda Guerra Mundial, Ortega logró sobreponerse a la deriva escéptica y al sentimiento de pesimismo en el que se sumieron, durante esos años de oscuridad y destrucción, los intelectuales europeístas de su generación. Así pues, el comienzo de la década de los '50 coincide -como ha señalado José Luis Molinuevo- con “la recuperación por parte de Ortega de su propia idea de vida, insertándola en los ideales de la gran cultura europea: humanismo, universalismo y cosmopolitismo” (Molinuevo, 2000: 12).

La ocasión de presentar en público su visión renovada (y madurada) de la técnica se le presentaría a Ortega en un congreso de arquitectos alemanes titulado: "El hombre y el espacio”, y que tuvo lugar en la ciudad alemana de Darmstadt el 5 de agosto de 1951. En este congreso se planteaba la interrogante de cómo habitar el espacio de lo humano, y más concretamente, cómo construir en una Europa en ruinas. De la repercusión alcanzada por este encuentro científico podemos hacernos una idea por la cobertura informativa y la crónica que días más tarde haría del mismo el Frankfurter Allgemeine Zeitung, publicada el 8 de agosto de 1951. Sin embargo, pese al enorme interés que suscitó este evento, difícilmente hubiera tenido mayor importancia de no haber coincidido en él dos de los intelectuales europeos de mayor prestigio en ese momento: Martin Heidegger y José Ortega y Gasset. De hecho, en lo sucesivo, a este encuentro científico se le conocería como el "Coloquio de Darmstadt", precisamente para rememorar el debate mantenido por sus dos ponentes estrella sobre el hombre y la técnica. De las conferencias dictadas por ambos pensadores cabe inferir que ambos mantienen una distancia escéptica en torno a las posibilidades de una técnica autónoma. Por otra parte, tanto Heidegger como Ortega están de acuerdo en considerar la técnica desde la perspectiva de la historicidad, y atienden a la especificidad de la técnica moderna como fenómeno histórico que tiene un origen y un posible final. Ahora bien, al margen de esta coincidencia de pareceres sobre el aspecto temporal de la técnica, la meditación que hacen estos dos autores de la técnica arroja resultados diametralmente opuestos (Regalado, 1990: 275). 
Llano Alonso, Fernando H.: “El hombre y la técnica en Ortega y Gasset”, IUS ET SCIENTIA, 2015, Vol. 1, No. 1, pp. 1-24

DOI: http://dx.doi.org/10.12795/IETSCIENTIA.2015.i01.02

En su conferencia, titulada “Construir, habitar, pensar”, que tiene como trasfondo su Carta sobre el humanismo (1946), Heidegger mantenía que se construye para habitar, como medio para un fin, pero este fin, que es habitar, preexiste al construir. "Habitar y construir están el uno con respecto al otro en la relación de fin a medio”. El hombre construye en el mundo que habita, en la medida en que habitar es la única forma que tienen los hombres de ser en la tierra (Heidegger, 1994: 128). Es decir, para el filósofo alemán, el “yo soy” (ich bin) equivale al "yo habito" (ich wohne). Al mismo tiempo, habitar es cuidar la tierra, pero la tierra es sólo uno de los cuatro elementos, los cuales forman a su vez un todo a partir de la unidad original, la Divinidad que se oculta. Y es aquí donde aparece la técnica, en la medida en que, para Heidegger, "la técnica es un modo de salir de lo oculto”, y sólo allí donde se da este desvelar acaece de un modo propio lo verdadero (Heidegger, 1994: 15). La técnica es, pues, hacer venir algo no presente a la presencia. Más allá del artefacto y del ars, atiende a un cierto advenir desde lo alto. La tecné, o sea, la producción, es utilizada para hacer aparecer lo que está oculto, y el técnico viene a ser un Sócrates que asiste a ese alumbramiento. Por lo tanto, el hombre es, en su habitar, un guardián celoso del hogar mundano. El guardar y cuidar se entienden ligados al invocar el ser. Tecnificar es invocar la aparición del ser. Pero el hombre no produce al ser, sino que invoca al ser para que éste se produzca. Una vez más Heidegger, al igual que hizo anteriormente en la Carta sobre el humanismo, vuelve a colocarnos ante el dilema de tener que optar por el hombre o por el ser, y esta cuestión es decisiva a la hora de elegir por qué, para qué, para quién y cómo se construye.

Al contrario que Heidegger, para Ortega, el carácter del hombre es más creador. El hombre está vivo en la medida que crea y está entregado a la producción artificial de una sobrenaturaleza en la que pueda proyectar su ser. En este sentido, la tesis de Ortega es que la tierra es originariamente inhabitable (unbewohnbar) para el hombre, el cual, a diferencia del animal, no tiene hábitat. "El hombre no tiene una Physis, una naturaleza como acaso la tienen el animal, la planta y el mineral” (VI, 780), ni tampoco existe un espacio de lo humano como espacio natural. El hombre es, por tanto, un inadaptado, "un intruso en la llamada naturaleza”. El habitar esa naturaleza no es, por consiguiente, una realidad (como sostenía Heidegger), sino una aspiración, un deseo, una ilusión. A mayor abundamiento, para nuestro autor, "sólo la técnica, sólo el construir -bauen- asimila el espacio al hombre, lo humaniza" (X, 379). Únicamente la técnica humaniza el espacio heterogéneo y lo hace estable. Por eso, al crear la sobrenaturaleza (o naturaleza artificial) el hombre transforma su circunstancia y la adapta a sus necesidades, porque el hombre no quiere habitar -wohnen- el mundo, ni 
Llano Alonso, Fernando H.: “El hombre y la técnica en Ortega y Gasset”, IUS ET SCIENTIA, 2015, Vol. 1, No. 1, pp. 1-24

DOI: http://dx.doi.org/10.12795/IETSCIENTIA.2015.i01.02

tampoco tiene un especial empeño por estar en él a toda costa, pues lo que en realidad desea es estar bien. De ahí que concluya su conferencia en Darmstadt, titulada: "El mito del hombre allende la técnica” (1952), afirmando que:

“Este mito [Ortega se refiere al hombre] nos muestra la victoria de la técnica: ésta quiere crear un mundo nuevo para nosotros, porque el mundo originario no nos va, porque en él hemos enfermado. El nuevo mundo de la técnica es, por tanto, como un gigantesco aparato ortopédico que ustedes, los técnicos, quieren crear, y toda técnica tiene esta maravillosa y -como todo en el hombre- dramática tendencia y cualidad de ser una fabulosa y grande ortopedia” (VI, 817).

\section{LA CONTEMPORANEIDAD DE LA TESIS ORTEGUIANA SOBRE LA TÉCNICA}

Anteriormente se ha podido comprobar cómo, frente a la actitud recelosa contra la técnica adoptada por otros pensadores contemporáneos de Ortega, el filósofo madrileño asimilaba la técnica al proyecto humanista, convirtiéndola así en el remedio más eficaz para redimir al Humanismo de su crisis y reconfigurarlo para nuestro tiempo. En otras palabras: aunque Ortega nunca llegaría al extremo de convertirse en un defensor a ultranza del positivismo científico (como en el caso de Auguste Comte), sí consideraba a la ciencia un componente esencial del hombre moderno (Navajas, 2007: 5). Por lo tanto, nuestro autor no tenía inconveniente en reconocer los beneficios y las posibilidades que la técnica puede reportar al hombre -entre otras cosas porque, como se recordará, "la misión inicial de la técnica es ésa: dar franquía al hombre para poder vacar a ser sí mismo” (V, 575). Ahora bien, aunque Ortega reconocía los logros de la técnica y sus posibilidades ilimitadas, lo que no estaba dispuesto a avalar era ni "la barbarie del especialismo", ni el vaciamiento de los contenidos culturales de la técnica que caracterizan al nuevo tecnicismo (IV, 441 ss.). A los beatos de la técnica, que son aquellos que viven de su fe en la técnica y sólo en ella, habría que prevenirles del riesgo que supone vivir una vida vacía, porque: “ser técnico y sólo técnico es poder serlo todo y consecuentemente no ser nada determinado” (IV, 596). De ahí que, al ser plenamente consciente del peligro que comporta la apuesta del hombre masa por una técnica deshumanizada, el pensador madrileño termine su Meditación de la técnica escribiendo: "la vida no es sólo la lucha con la materia, sino la lucha del hombre con su alma” (IV, 605).

Al hilo del humanismo tecnológico de Ortega, y sobre todo, teniendo en cuenta la importancia que nuestro autor le concede a la técnica en la creación de la sobrenaturaleza 
Llano Alonso, Fernando H.: “El hombre y la técnica en Ortega y Gasset”, IUS ET SCIENTIA, 2015, Vol. 1, No. 1 , pp. 1-24

humana, en la que el medio se adapta al sujeto y éste es capaz de afrontar su circunstancia, no se entiende la relectura que ha hecho recientemente Sloterdijk del debate sobre el hombre y la técnica mantenido entre Heidegger y Ortega en 1951, y mucho menos si es para justificar su causa tecnocrática y antihumanista. Como es sabido, para Sloterdijk, el principal mérito de Heidegger consistía en haber intentado buscar la esencia humana más allá del humanismo, y en haber planteado la cuestión decisiva sobre quién va a “domesticar” a los seres humanos una vez que el humanismo ha fracasado. Por otra parte, el filósofo alemán parece inspirarse en la idea orteguiana de la sobrenaturaleza humana y de la autofabricación del hombre para cimentar su concepción de la autogénesis humana. En relación con esta relectura poshumanista, se ha comentado recientemente que Sloterdijk no sale bien parado de la contradicción consistente en exigir, por un lado, la rebaja de las ínfulas humanistas, desde el momento en que se va nivelando tendencialmente la diferencia entre el hombre y las cosas, y por otro lado, auspiciar la autorreferencialidad del hombre, el cual no sólo estaría a punto de reconocerse a sí mismo en su propia hechura fontanal, gracias fundamentalmente al descubrimiento del mapa del genoma humano, sino que estaría dispuesto también a manipular su cuerpo y mente para eliminar posibles disfunciones y mejorar sus capacidades. En definitiva, como ha señalado Félix Duque: "no se puede ser seguidor de un Heidegger cruzado con un "franciscanismo” tecnológico, o sea: un amigo de las “cosas mismas” -de las que ha de cuidar el hombre para recogerlas en el aprisco del "ser"-, y pretender al mismo tiempo ser oyente de la palabra -católica de Rehner- y -laica- de Ortega: las dos, empero, aunque por distintas razones, homocéntricas” (Duque, 2002: 170-171).

Sin embargo, conviene añadir que la mayoría de los estudios que se han realizado en los últimos años en torno a la tesis orteguiana sobre la técnica, coinciden en resaltar el mérito del pensador español, sobre todo por haber anticipado la importancia de la función que le correspondería tener en el futuro a la técnica en la sociedad de la información: la humanización del nuevo espacio (artificial en tanto que sobrenatural) en el que se desarrollará la vida social en plena era de la globalización, las Nuevas Tecnologías (NT), y las Tecnologías de la Información y la Comunicación (TIC), y que -para gran parte de los especialistas en la Meditación de la técnica- constituyen, sin duda, un excelente ejemplo de “nueva circunstancia” (Molinuevo, 2000: 18; Echeverría, 2000: 19, Atencia, 2003: 80; Navajas, 2007: 3 ss.; Mermall, 2010: 130-131). En este renovado contexto circunstancial, como ha indicado oportunamente Javier Echeverría, las propuestas de Ortega sobre la técnica adquieren nuevo brillo y actualidad al contrastarlas con la profunda transformación social suscitada por las TIC (teléfono, televisión, dinero electrónico, Internet...). Efectivamente, en 
Llano Alonso, Fernando H.: "El hombre y la técnica en Ortega y Gasset”, IUS ET SCIENTIA, 2015, Vol. 1, No. 1, pp. 1-24

DOI: http://dx.doi.org/10.12795/IETSCIENTIA.2015.i01.02

los países tecnológicamente desarrollados, los conceptos de circunstancia y necesidad han cambiado radicalmente, porque está surgiendo "un entorno tecnológico que se convierte en una nueva circunstancia” (Echeverría, 2000: 20).

El hombre contemporáneo se encuentra ante un mundo tecnológico al que, por una parte, tiene que adaptarse, pero al que también debe intentar transformar para hacerlo más humano. El problema actual no consiste, como venía sucediendo hasta bien entrado el siglo $\mathrm{XX}$, en saber de qué manera puede dominar el hombre la naturaleza; hoy en día, la novedad principal -o, por decirlo orteguianamente, "el tema de nuestro tiempo"- consiste en que somos conscientes de que la tecnología no solo transforma la naturaleza, sino también la sociedad, aunque no siempre sea para bien. En efecto, muchas modalidades de sobrenaturaleza forman parte de nuestra circunstancia hodierna (los medios de transporte, las redes de suministro energético, las TIC...), por lo que este hecho genera en nosotros a veces una sensación de dependencia respecto a la técnica, mayor incluso que nuestro sentido de sometimiento a la naturaleza. Este sentimiento de ambivalencia que nos provoca a nivel individual el mundo tecnológico, puesto que nos parece en parte indispensable y en parte rechazable, se ve potenciado en la sociedad de la información. En este sentido, algunos autores han opinado que el hombre de la era tecnológica debería interactuar con esa sobrenaturaleza artificial que ha creado con su inteligencia, y que es la consecutio de la acción del homo cogitans, pero sin que por ello haya que sucumbir ni al mensaje apocalíptico y antitecnológico, que es tan característico de los neo-orwellianos, ni a la quimera neoutopista que hoy encarnan "los aprendices de brujo del negropontismo", aprovechando la crisis de la cultura occidental a raíz de la pérdida de los valores e ideales defendidos por el humanismo ilustrado (Frosini, 1986: 154-155; Sartori, 1997: 232-235).

Entre las ideas más originales aportadas por Ortega en relación con la técnica, hay dos que son ciertamente relevantes por su actualidad: la idea de sobrenaturaleza y la de necesidad artificial (o superflua). Ambas ideas sirven en realidad para facilitar el arraigo del hombre naturalmente inadaptado dentro de la sociedad tecnológica, y expresan, en definitiva, su confianza en que este mundo de las Nuevas Tecnologías sea compatible tanto con el legado cultural del humanismo, como con el proyecto de la modernidad. Precisamente, la imagen utópica de una futura sociedad computerizada e informatizada, al fin libre del poder dominante del control tecnológico del Estado automatizado, ilustra el concepto de "Computopía” (computer-based utopia) acuñado por Yoneji Masuda en su libro: The Information Society as Post-Industrial Society (1980). Masuda, que a diferencia de Ortega cree en la simbiosis pacífica entre el hombre y la naturaleza, comparte con el filósofo español 
Llano Alonso, Fernando H.: “El hombre y la técnica en Ortega y Gasset”, IUS ET SCIENTIA, 2015, Vol. 1, No. 1 , pp. 1-24

DOI: http://dx.doi.org/10.12795/IETSCIENTIA.2015.i01.02

el ideal dinámico del humanismo tecnológico (al que denomina "sinergismo teológico”). Este ideal se orienta a la construcción de una sociedad sinérgica terrestre, física y no celeste, un espacio de información global que prevalezca sobre los conflictos, los intereses y las diferencias nacionales, y que paulatinamente “se irá enraizando, amplia y profundamente, en las mentes de las personas” (Masuda, 1984: 89).

Las tesis que postulan el humanismo tecnológico, que van desde Ortega a Masuda, tienen el atractivo de aportar rasgos caracterizadores básicos sobre el presente y el futuro de las libertades en la sociedad tecnológica. A propósito de esta visión liberal y humanista de la técnica, materializada, según Ortega, en la sobrenaturaleza tecnológica inventada por el hombre y, en el caso de Masuda, en la Computopía, Antonio E. Pérez Luño ha destacado la relevancia de este enfoque teórico porque, "más allá de las posibilidades de realización more tecnológico de su prognosis sobre el futuro de las sociedades avanzadas”, nos ofrece un marco de estudio para el significado actual de los derechos humanos de la tercera generación, y nos aporta motivos de reflexión en torno a las cuestiones jurídicas y políticas que se engloban bajo el rótulo de la “teledemocracia” (Pérez Luño, 2012: 45).

\section{CONCLUSIÓN}

A lo largo del presente capítulo se ha podido comprobar cómo Ortega, el mismo autor que proclama en 1930 el predominio de las “masas” sobre las “minorías selectas”, evita caer, sin embargo, en la actitud apocalíptica tan propia de aquellos que, como afirma Umberto Eco, “sobreviven precisamente elaborando teorías sobre la decadencia” (Eco, 1995: 28). Ahora bien, aunque Ortega no niega la realidad del progreso, e incluso de sus beneficios para la humanidad, no está dispuesto -como proponen los integrados- a que el desarrollo tecnológico y el avance de la ciencia se produzcan a cualquier precio, y mucho menos a costa del sacrificio de la cultura en el sentido amplio del término. Entre el aristocratismo de las elites intelectuales y el primitivismo del hombre-masa debe haber un punto intermedio desde el cual se pueda contemplar con razonable optimismo el futuro de la sociedad tecnológica. Anteriormente hemos visto cómo, en el fondo de La rebelión de las masas, pueden encontrarse los fundamentos ontológicos de la técnica según Ortega, que luego devendrá en la tesis de la sobrenaturaleza humana.

Se ha llamado la atención sobre las posibles consecuencias que este proceso de naturalización de la técnica puede tener en la relación hombre-entorno, en la medida en que la dependencia del individuo de las Nuevas Tecnologías ha llegado a tal punto que algunos 
Llano Alonso, Fernando H.: “El hombre y la técnica en Ortega y Gasset”, IUS ET SCIENTIA, 2015, Vol. 1, No. 1, pp. 1-24

DOI: http://dx.doi.org/10.12795/IETSCIENTIA.2015.i01.02

críticos no han dudado en denunciar el fenómeno de la "adicción tecnológica”, una suerte de “absoluta esclavitud a los medios de comunicación” a la que se hallan sometidos no sólo los más jóvenes, sino también los adultos de la generación actual (Mermall, 2010: 130). En este mundo de hoy, dominado por las TIC, donde los hombres parecen vivir en permanente estado de alteración y a penas les queda espacio para la intimidad, el recogimiento y la soledad, sería conveniente tener en cuenta la oposición planteada por Ortega entre civilización y barbarie en los términos de ensimismamiento y alteración. En este sentido, recuérdese cómo, para Ortega, lo que distingue a los seres humanos del resto de los animales es, precisamente, su capacidad para ensimismarse y experimentar su propio mundo interior ${ }^{9}$. Por eso, ante el avance de la interpretación cientificista (o “tecnicista”) de la técnica, que propicia la disociación entre el hombre y la técnica, y confunde la cultura y el tecnicismo (I, 68), Ortega reivindica la humanización de la técnica, es decir, la revalorización del nuevo humanismo en la futura sociedad tecnológica $(\mathrm{V}, 599)$.

El humanismo que invoca Ortega no se corresponde, por cierto, con el modelo clásico del siglo XV, cuyo afán consistía en volver al pasado, a lo antiguo, a la cultura greco-romana y al cristianismo primitivo (V, 263; VI, 506) $)^{10}$. El humanismo de Ortega no es arqueológico ni regresivo, sino un neohumanismo que ensaya y vislumbra el porvenir de lo humano. Por eso, en su particular enfoque humanista, Ortega se encuentra más cerca de Goethe que de Pico della Mirandola (VI, 555). El humanismo orteguiano no es, por tanto, “un neoidealismo que demoniza la técnica” (Molinuevo, 2002: 253). Como ha puesto de manifiesto José Luis Molinuevo, la meditación sobre la técnica que lleva a cabo nuestro autor desde los años treinta a los cincuenta va acompañada de la convicción de que el modelo de pensamiento occidental que crearon los griegos está agotado. Sin embargo, Ortega ve en la combinación del progreso técnico con las humanidades (un neologismo que, según el pensador madrileño, “nos consigna directamente a los fenómenos en que la realidad humana aparece”) una gran oportunidad para la creación o la invención de un mundo nuevo en el que los hombres no tendrán que enfrentarse al dilema de dominar o someterse a la naturaleza, sino que deberán

\footnotetext{
${ }^{9}$ En este sentido, como señala Ciriaco Morón, el ensimismamiento, o sea, la vuelta reflexiva al yo es considerada por Ortega como "la nota específicamente humana”. (Morón, 1968: 165).

10 “Tal es el espíritu con que comienza la reforma religiosa y el humanismo. No son impulsos hacia el futuro, sino todo lo contrario. Cerrado el futuro, forzoso algún cambio, sólo es posible el retorno. Se vuelve a lo antiguo, pero no como se suele repetir, sólo a la cultura greco-romana por ser tal cultura, sino a todo lo primitivo. Ya Petrarca, cuando tocaba el clarín de retorno a lo antiguo, une a los clásicos los Padres de la Iglesia, y Conrado Celtis mezclará la resurrección de griegos y romanos a la del germanismo primitivo y Erasmo se dedicará a editar los Padres de la Iglesia y los libros primeros del cristianismo” (VI, 506).
} 
Llano Alonso, Fernando H.: “El hombre y la técnica en Ortega y Gasset”, IUS ET SCIENTIA, 2015, Vol. 1, No. 1 , pp. 1-24

DOI: http://dx.doi.org/10.12795/IETSCIENTIA.2015.i01.02

afrontar otro desafío distinto: el que representa esa "sobrenaturaleza" que constituyen las nuevas tecnologías.

A propósito de este nuevo horizonte que, merced a la técnica humana, se abre ante el hombre -ese "animal fantástico" en el que confluyen la imaginación y la fantasía, quisiera concluir trayendo a colación la palabras finales de uno de los últimos trabajos escritos por Ortega, "Pasado y porvenir del hombre actual" (1951), y que suponen toda una esperanzadora declaración de principios en relación con la futura sociedad tecnológica que él atisbaba en las postrimerías de su vida:

“Nuestra civilización sabe que sus principios están en quiebra -desmaterializados-, y por eso duda de sí misma (...) Todo esto significa claramente que la forma cultivada hasta aquí por nuestra civilización -o con más exactitud por los occidentales- está agotada y exhausta, pero que, por ello mismo, nuestra civilización se siente impulsada y obligada a inventar formas radicalmente nuevas. Hemos llegado a un momento, señoras y señores, en el que no tenemos más remedio que inventar, e inventar en todos los órdenes. No se podría proponer tarea más deliciosa. ¡Hay que inventar!” (VI, 794).

\section{BIBLIOGRAFÍA}

- ATENCIA PÁEZ, José María (2003), “Ortega y Gasset, meditador de la técnica”, Argumentos de Razón Técnica, nº 3, pp. 61-95.

- BELL, Daniel (1973), The Coming of Post-Industrial Society: A Venture in Social Forecasting, Basic Books, New York.

- BRONCANO, F. (2000), Mundos artificiales. Filosofía del cambio tecnológico, Paidós, México D.F.

- CORDERO DEL CAMPO, Miguel Ángel (2002), “La idea de técnica en Ortega”, Revista de Estudios Orteguianos, nº 5, pp. 169-181.

- DUQUE, Félix (2002), En torno al humanismo. Heidegger, Gadamer, Sloterdijk, Tecnos, Madrid.

- ECHEVERRÍA, Javier (2002), “Sobrenaturaleza y sociedad de la información: la Meditación de la técnica a finales del siglo XX”, Revista de Occidente, 228 (2000), pp. 19-32. 
Llano Alonso, Fernando H.: “El hombre y la técnica en Ortega y Gasset”, IUS ET SCIENTIA, 2015, Vol. 1, No. 1, pp. 1-24

DOI: http://dx.doi.org/10.12795/IETSCIENTIA.2015.i01.02

- ECO, Umberto, Apocalittici e integrati (1965), trad. esp. A. Boglar, Lumen/Tusquets, 1995.

- ELLUL, Jacques (1962), “The Technological Order”, Technology and Culture, $\mathrm{n}^{\circ}$ 3, pp. 394-421.

- FROSINI, Vittorio (1986), L'uomo artificiale. Etica e diritto nell'era planetaria, Spirali, Milano.

- GRIMAL, Pierre (1982), Mitologías. Del Mediterráneo al Ganges (Vol. 1), trad. esp. J. Ma Valverde, Planeta, Barcelona.

- HABERMAS, Jürgen (1965), “Technischer Fortschritt und soziale Lebenswelt”, en Technik und Wissenschaft als “ideologie”, Suhrkamp Verlag, Frankfurt am Main, 1979.

- HABERMAS, Jürgen (1998), La posmodernidad, trad. esp. J. Fibla, Kairós, Barcelona.

- HEIDEGGER, Martin (1989), Entrevista del “Spiegel”, trad. esp. R. Rodríguez, Tecnos, Madrid.

- HEIDEGGER, Martin Conferencia y artículos (1994), trad. esp. E. Barjau, Ediciones del Serbal, Barcelona, 1994.

- HEIDEGGER, “El final de la Filosofía y la tarea de pensar”, en Tiempo y ser (1962), trad. esp. J. L. Molinuevo, Tecnos, Madrid, 1999.

- MARCUSE, Herbert (1964), One-Dimensional Man. Studies in the Ideology of Advanced Industrial Society, Beacon Press, Boston.

- MASUDA, Yoneji (1984), La sociedad informatizada como sociedad post-industrial, trad. esp. J. Ollero, Fundesco-Tecnos, Madrid.

- MERMALL, Thomas (2010), “Ortega contra Pero Grullo: Estrategias retóricas en Meditación de la técnica”, Revista de Estudios Orteguianos, nº 21, pp. 119-132.

- MOLINUEVO, José Luis (2000), “Ortega y la posibilidad de un humanismo tecnológico”, Revista de Occidente, $\mathrm{n}^{\circ}$ 228, pp. 5-18.

- $\quad$ MOLINUEVO, J. L., Para leer a Ortega, Alianza Editorial, Madrid, 2002.

- MORO ESTEBAN, Pedro Luis (2001), "La crisis del deseo: La rebelión de las masas a la luz de Meditación de la técnica”, Revista de Estudios Orteguianos, n² 2, pp. 215222.

- MORÓN ARROYO, Ciriaco (1968), El sistema de Ortega y Gasset, Ediciones Alcalá, Madrid, 1968. 
Llano Alonso, Fernando H.: “El hombre y la técnica en Ortega y Gasset”, IUS ET SCIENTIA, 2015, Vol. 1, No. 1 , pp. 1-24

DOI: http://dx.doi.org/10.12795/IETSCIENTIA.2015.i01.02

- $\quad$ MUMFORD, Lewis (1934), Technics and Civilization, Harcour, Brace \& Co. Inc., New York.

- NAVAJAS, Gonzalo, “Ortega y Gasset, la técnica y la nueva comunicación”, Biblioteca Virtual Miguel de Cervantes/Asociación Internacional de Hispanistas, Alicante, 2007. http://www.cervantesvirtual/obra/ortega-y-gasset-la-tcnica-y-lanueva-comunicacin-0/ Visitado el 11/11/2015.

ORTEGA Y GASSET, José (2004-2010), Obras completas (en diez volúmenes), Taurus/Fundación José Ortega y Gasset, Madrid.

- “La universidad española y la universidad alemana” (1906), I, pp. 63-77.

- La rebelión de las masas (1930), IV, pp. 347-528.

- “Del Humanismo y de la generación cartesiana” (1933), V, pp. 260-264.

- Ensimismamiento y alteración (1939), V, pp. 525-605.

- Meditación de la técnica (1939), V, pp. 551-605.

- Historia como sistema (1941), VI, pp. 45-81.

- En torno a Galileo (1947), VI, pp. 371-506.

- "Sobre un Goethe bicentenario" (1949), VI, 549-576.

- "Pasado y porvenir del hombre actual” (1951), VI, 778-794.

- “En torno al coloquio de Darmstadt. 1951” (1952), 797-811.

- “El mito del hombre allende la técnica” (1952), VI, 811-817.

- PÉREZ LUÑO, Antonio Enrique (2004), ¿Ciberciudadanía o ciudadaní@.com?, Gedisa, Barcelona.

- PÉREZ LUÑO, Antonio Enrique (2012), Los derechos humanos en la sociedad tecnológica, Editorial Universitas, Madrid.

- PIRO, Pietro (2012), Non c'è tempo per l'uomo. Una discesa nel maesltröm della tecnica, Edizioni La Zisa, Palermo.

- REGALADO, Antonio (1990), El laberinto de la razón. Ortega y Heidegger, Alianza, Madrid.

- RIU, Federico (2010), Ensayos sobre la técnica en Ortega, Heidegger, García Bacca, Mayz, Anthropos, Barcelona.

- SARTORI, Giovanni (1997), Homo videns. La sociedad teledirigida, trad. esp. A. Díaz Soler, Punto de Lectura (Santillana Ediciones Generales), Madrid.

- SLOTERDIJK, Peter (2003), Normas para el parque humano. Una respuesta a la Carta sobre el humanismo de Heidegger, trad. esp. T. Rocha Barco, Siruela, Madrid. 
Llano Alonso, Fernando H.: “El hombre y la técnica en Ortega y Gasset”, IUS ET SCIENTIA, 2015, Vol. 1, No. 1 , pp. 1-24

DOI: http://dx.doi.org/10.12795/IETSCIENTIA.2015.i01.02

- $\quad$ SMITH, Merritt Roe y Leo MARX (eds.) (1994, Does Technology Drive History?

The Dilemma of Technological Determinism, M.I.T. Press, Cambridge (Massachusetts).

- SPENGLER, Oswald (1993), La decadencia de Occidente. Bosquejo de una morfología de la Historia universal (1917), Vol. II, trad. esp. M. García Morente, Planeta-Agostini, Barcelona.

- SPENGLER, Oswald (1967), El hombre y la técnica (1931), trad. esp. M. García Morente, Espasa-Calpe, Madrid.

- $\quad$ von KLINCKOWSTROEM, Carl (1980), Historia de la técnica. Del descubrimiento del fuego a la conquista del espacio, trad. esp. L. Correal, Labor, Barcelona.

- WINNER, Langdon (1977), Autonomous Technology: Technics-out-of-Control as a Theme in Political Thought, M.I.T. Press, Cambridge (Massachusetts).

- WINNER, Langdon (1986), The Whale and the Reactor: A Search for Limits in an Age of High Technology, University of Chicago Press, Chicago. 